\title{
Bortezomib treatment causes long-term testicular dysfunction in young male mice
}

\author{
Mi Hou ${ }^{1 *}$, Emma Eriksson ${ }^{1}$, Konstantin Svechnikov ${ }^{1}$, Kirsi Jahnukainen ${ }^{1,2}$, Olle Söder ${ }^{1}$, Andreas Meinhardt ${ }^{3}$ \\ and Lars Sävendahl ${ }^{1}$
}

\begin{abstract}
Background: With increased long-term survivors of childhood cancer patients, therapy-associated infertility has become one of the most common late side-effects and significantly affects their life-quality. Therefore, evaluation of anti-cancer agents on male reproduction and infertility prevention are urgently demanding. The proteasome inhibitor bortezomib has been launched in clinical trials for childhood cancers, however, its potential side effects on reproduction have so far been neither investigated experimentally nor reported in treated children. Thus the present study is designed to explore the impact of bortezomib on male reproductive function and to gain insights into how bortezomib exerts its adverse effects on man gonad, thereby providing pediatric oncologists relevant information.

Methods: 35 day-old male mice were treated with one 11-day cycle of bortezomib and then sacrificed 2 days, 45 days, or 6 months later. A mating study was performed in the group followed for 6 months, and their pups were analyzed on postnatal day 50. Serum follicle-stimulating hormone (FSH) and testicular testosterone levels were measured. Testicular morphology was evaluated by light- and electron microscopy, and the underlying mechanisms and pathways of testis damage were investigated.
\end{abstract}

Results: Testicular damage was visible already 2 days after stopping bortezomib and increased in severity by day 45. Then $80 \%$ of seminiferous tubules exhibited hypospermatogenesis with arrest at the levels of spermatogonia, spermatocytes and round spermatids. Germ cells were specifically targeted by bortezomib as evidenced by increased apoptosis mediated through activation of p53 and caspases. Even six months after the bortezomib treatment, testis weight, sperm concentration and seminiferous tubule length remained at a decreased level, indicating that spermatogenesis and tubular outgrowth could not fully recover. Combined with persistently increased serum levels of FSH in these mice, our results demonstrate that bortezomib can have long-term effects on testicular function, although fertility of bortezomib-exposed males remained and their offspring looked healthy.

Conclusion: Bortezomib treatment causes long-term gonadal dysfunction in male mice. Careful monitoring of gonadal function in male childhood cancer patients treated with bortezomib is thus strongly recommended.

Keywords: Proteasome inhibitor, Bortezomib, Cancer, Mouse, Testis

\footnotetext{
* Correspondence: Mi.Hou@ki.se

'Department of Women's and Children's Health, Astrid Lindgren Children's Hospital, Pediatric Endocrinology Unit Q2:08, Karolinska Institutet \& University Hospital, SE-171 76 Stockholm, Sweden

Full list of author information is available at the end of the article
} 


\section{Background}

Despite highly improved anti-cancer strategies and increasing numbers of cancer survivors, resistance of malignant cells to chemotherapeutic agents leading to relapsed and refractory cancer remains a major concern. In addition, infertility, one of the severe late side effects of intensive cancer treatment is also an unfavorable factor that negatively influences the quality of life among cancer survivors. Thus, new drugs for efficient treatment of relapse and refractory cancer with fewer side effects on the testis are highly desired.

The 26S proteasome is the enzymatic core engine of the ubiquitin and proteasome dependent proteolytic system (UPS), the major eukaryotic pathway for regulated protein degradation. The UPS plays a pivotal role in cellular protein turnover, protein quality control, antigen processing, signal transduction, cell cycle regulation, cell growth and survival, cell differentiation and apoptosis [1]. Selective degradation of proteins by UPS is a critical determinant for maintaining cellular homeostasis [2], and consequently, inhibition of the proteasome blocks the processes of protein degradation leading to accumulation of proteins that affect multiple signaling cascades within the cells, thereby resulting in cell death and prevention of tumor growth [3].

Bortezomib (Velcade ${ }^{\oplus}$, formerly known as PS-341, LDP-341 and MLM341) is an inhibitor of the 26S proteasome [4]. Due to its profound anti-tumor effects, bortezomib as the first proteasome inhibitor has entered into the clinic for treatment of adult multiple myeloma [5]. Promising results have been achieved from a phase II clinical trial in adult patients with relapsed or refractory indolent lymphoma [6]. In a recent phase I clinical study in relapsed childhood acute lymphatic leukemia, bortezomib was found to be efficacious when combined with traditional chemotherapeutic drugs [7].

Although the clinical efficacy of bortezomib is evident and many patients tolerate the treatment relatively well, some serious adverse effects, such as neutropenia, thrombocytopenia and heart failure, have been reported [8]. In addition, experimental data have shown that bortezomib selectively targets growth plate chondrocytes, thereby leading to permanent growth failure in young male mice [9]. So far, it is unknown if bortezomib may also impair testicular function and fertility.

During gonadal and germ cell differentiation, ubiquitin, the ubiquitin activating and conjugating enzymes E1, E2, and UBC4, and the ubiquitin C-terminal hydrolase L1 (UCH L1) are all highly expressed by Sertoli cells, spermatogonia, spermatocytes, and spermatids [10]. The UPS is required for the degradation of numerous proteins throughout the mitotic, meiotic and postmeiotic developmental phases of spermatogenesis [11]. The activity of the UPS is high during spermatogenesis [12] due to the demanding requirement of massive breakdown of cytoplasmatic and nuclear proteins during this process [13-15]. Consistent with its multiple functions, alterations of the UPS have been implicated in many pathological processes and sub/infertility. Indeed, it has been observed that targeted disruption of the polyubiquitin gene $U b b$ results in male and female infertility [16] and altered testicular gene expression patterns [17]. Loss of UCHL1, a deubiquitating enzyme responsible for regenerating monoubiquitin from the ubiquitin-protein complex, decreased the rate of apoptosis in the first round of spermatogenesis and increased the numbers of premeiotic germ cells in immature mice [18], whereas asymmetric distribution of UCHL1 in spermatogonia is associated with maintenance and differentiation of spermatogonial stem cells [19]. In contrast, overexpression of UCHL1 was accompanied by reduced PCNA expression and abolishment of apoptosis in spermatogonia, and spermatogenesis was blocked [20]. Moreover, mice lacking the UBC4-testis gene have a delay in postnatal testis development [21]. Based on these reports, we hypothesized that inhibition of the $26 \mathrm{~S}$ proteasome, the core engine of the UPS would lead to deleterious effects on testicular function. To address this, we designed a study, in which a single cycle of a clinically relevant dose of bortezomib was administered to young male mice at the age of 35 days. Our intent was to evaluate whether bortezomib has testicular effects and impairs fertility of bortezomibexposed males, and/or has potential impacts on their offspring.

\section{Results}

\section{Bortezomib reduces testicular weight and sperm} concentration

A statistically significant reduction in testicular weight and sperm concentration was observed in all groups treated with bortezomib when analyzed 2 days, 45 days, and 6 months after the last injection (Table 1) compared to controls, whereas body- and seminal vesicle weights were unaffected at all-time points examined (data not shown).

\section{Bortezomib causes germinal epithelial damage and decreases longitudinal growth of the pubertal seminiferous tubules}

Examination of testicular sections from mice killed 2 days after the last bortezomib injection revealed that approximately $30 \%$ of seminiferous tubules were damaged in 4 out of 5 mice examined. The majority of affected seminiferous tubules were located peripherally under the testicular capsule (Figure 1C and D). Impaired seminiferous tubules exhibited hypospermatogenesis with arrest (mixed atrophy) showing spermatogonia (5.8\%), spermatocyte $(8.7 \%)$, and round spermatid $(16.6 \%)$ as the most 
Table 1 Testis weight, sperm concentration and length of seminiferous tubule in bortezomib treated and control mice

\begin{tabular}{lllll}
\hline Follow-up period & Group & $\begin{array}{l}\text { Testis weight, both } \\
\text { sides }(\mathbf{m g}) \mathbf{n}=\mathbf{6}\end{array}$ & $\begin{array}{l}\text { Sperm concentration } \\
(\mathbf{1 0} / \mathbf{m l}) \mathbf{n}=\mathbf{6}\end{array}$ & $\begin{array}{l}\text { Length of seminiferous } \\
\text { tubules }(\mathbf{m}) \mathbf{n}=\mathbf{4}\end{array}$ \\
\hline 2 days & Control & $91 \pm 0.001$ & $3.30 \pm 0.543$ & $2.57 \pm 0.131$ \\
& Bortezomib & $83 \pm 0.002^{* * *}$ & $0.89 \pm 0.239^{*}$ & $2.36 \pm 0.235$ \\
45 days & Control & $120 \pm 0.003$ & $4.62 \pm 1.031$ & $2.78 \pm 0.103$ \\
& Bortezomib & $85 \pm 0.003^{* * *}$ & $1.31 \pm 0.148^{* * *}$ & $2.09 \pm 0.123^{*}$ \\
6 months & Control & $114 \pm 0.003$ & $11.73 \pm 2.027$ & $3.01 \pm 0.021$ \\
& Bortezomib & $80 \pm 0.006^{* * *}$ & $3.12 \pm 0.951^{* * *}$ & $2.40 \pm 0.272$ \\
\hline
\end{tabular}

Mean \pm S.E.M; ${ }^{* P}<0.05,{ }^{* * *} \mathrm{P}<0.001$.

advanced germ cell types in seminiferous tubule cross-sections examined, respectively. Only $54.4 \%$ of tubules displayed normal spermatogenesis. Altogether $15 \%$ of tubules showed a Sertoli cell only phenotype (SCO, Figure $1 \mathrm{C}$ and $\mathrm{D}$, arrows), no morphological abnormalities of Sertoli and Leydig cells (LCs) were observed. The length of the seminiferous tubules was comparable to control (Table 1). Severely impaired seminiferous epithelia with degenerating germ cells exfoliating in the lumen of seminiferous tubules were observed under electron microscopy (Figure 2D arrows).

Forty-five days after treatment, $80 \%$ of the crosssections of the seminiferous epithelium revealed a histopathological pattern of damage in all examined animals receiving bortezomib $(n=5$, Figure $1 \mathrm{E}$ and $\mathrm{F})$. SCO tubules were seen in 19.2\% (Figure 1E and F, arrows) with tubules showing spermatogonia (9.6\%), spermatocyte (20.1\%) and round spermatid (30.7\%) as the most advanced germ cell type accounted in the tubules examined, respectively. Only $19.2 \%$ of the examined tubules showed normal spermatogenesis. The length of seminiferous tubules in these mice was significantly decreased compared to the controls (Table 1). Electron microscopic examination of testicular sections of these mice revealed that germ cell loss had reduced the seminiferous epithelium to only one single basal cell layer (Figure 2E arrows). Remaining cells showed signs of degeneration, i.e. irregular nuclear outline.

Six months after the cessation of bortezomib treatment, $10-15 \%$ of seminiferous tubule cross-sections (mainly located subcapsularly) exhibited hypospermatogenesis with arrest at the level of round spermatids in 2 out of 4 mice examined. One mouse displayed $40-50 \%$ of seminiferous epithelial cross-sections with the same pattern of damage (Figure $1 \mathrm{G}$ and $\mathrm{H}$, arrows). Compared to the follow-up after 45 days, at 6 months the number of seminiferous tubules with normal spermatogenesis had increased from $19.2 \%$ to $55.4 \%$, whereas SCO tubules had

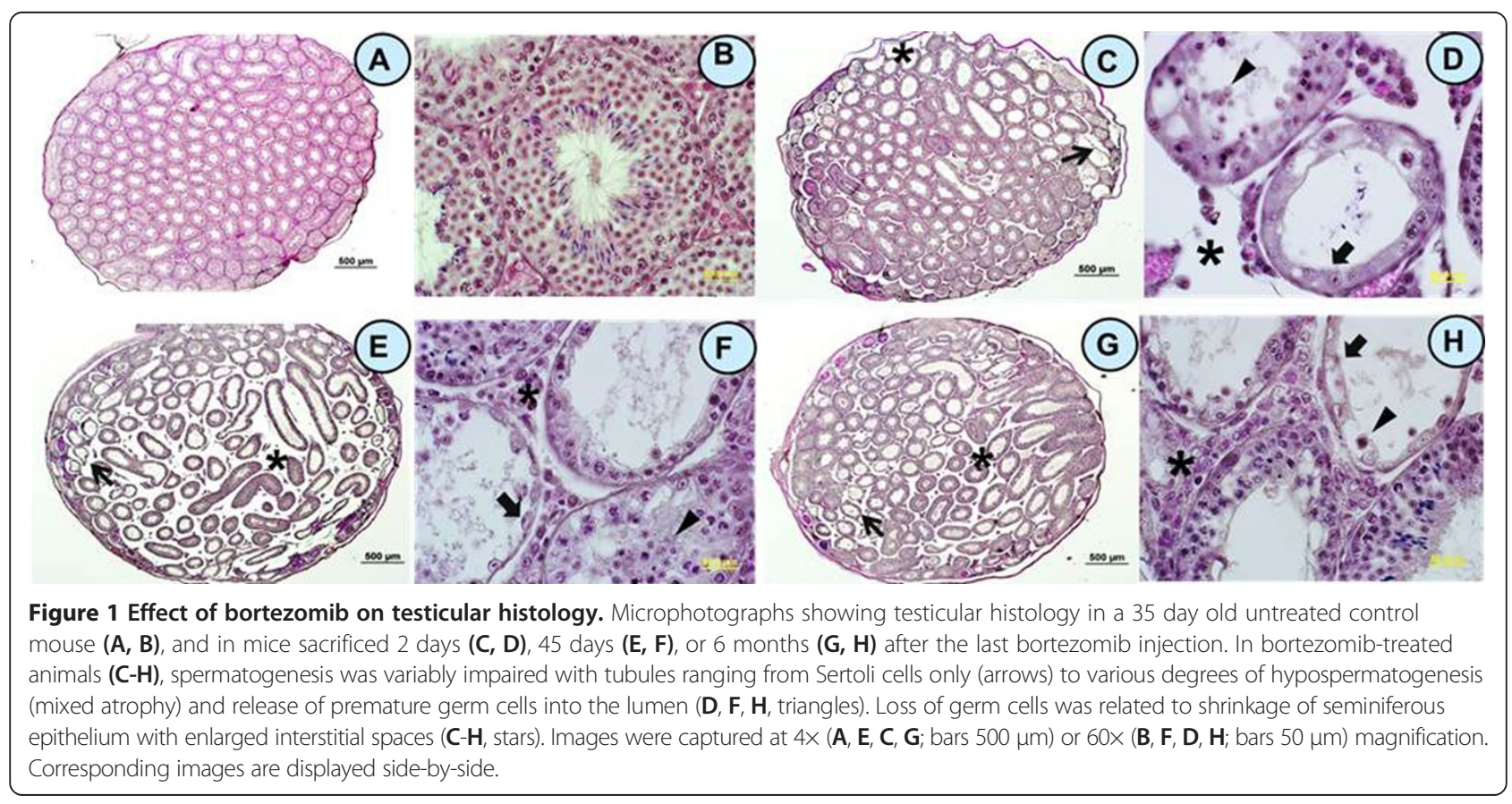




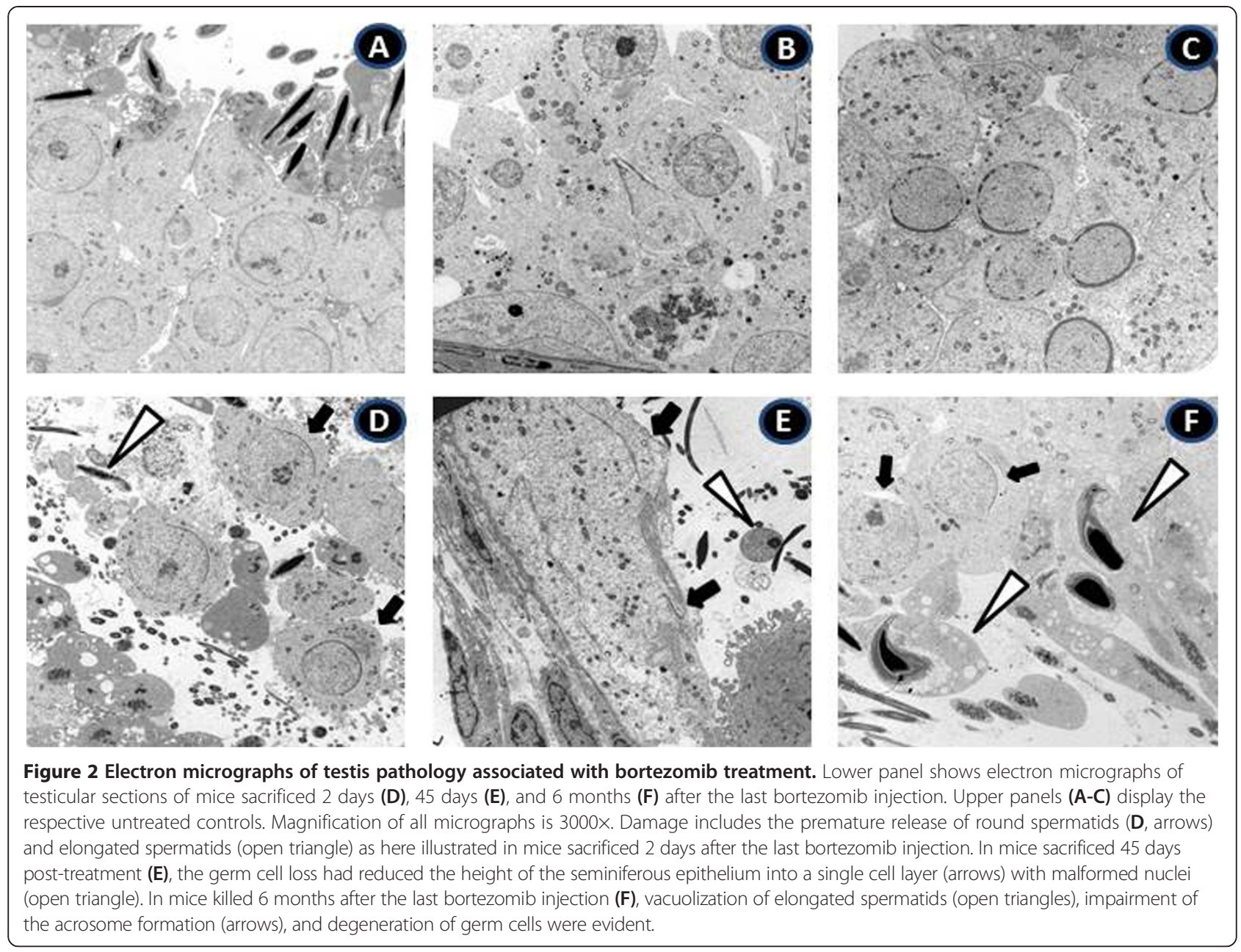

declined from $19.2 \%$ to $9.5 \%$. The percentage of seminiferous tubules that showed spermatogonia, spermatocyte and spermatids as the most advanced germ cell type in this group were $4.1 \%, 22.9 \%$ and $8.1 \%$, respectively. The length of seminiferous tubules increased from $2.09 \pm 0.12 \mathrm{~m}$ to $2.40 \pm 0.27 \mathrm{~m}$ but was still shorter than those in the control group $(3.01 \pm 0.02 \mathrm{~m}$, Table 1$)$ indicating that spermatogenesis and pubertal longitudinal growth of seminiferous tubule were only partially recovered. Electron microscopy showed numerous vacuoles in the cytoplasm of elongated spermatids and electron-lucent areas around the nuclei suggesting fluid accumulation (Figure 2F, open triangles). Acrosome formation was impaired in round spermatids (Figure $2 \mathrm{~F}$ arrows).

\section{Bortezomib treatment does not impair fertility}

To determine whether a single cycle of bortezomib administration impairs fertility, a mating study was performed 6 months later. This showed that 31\% (5 out of 16) of females mated with males who had been exposed to bortezomib became pregnant while $35 \%$ (7 out of 20) of those females mated with unexposed males became pregnant $(\mathrm{P}=0.86)$. The litter sizes in corresponding mother groups were 5.0 and 7.3 pups/mother $(P=0.07)$, respectively. This shows that despite decreased adult testicular volume and sperm counts, the fertility of bortezomib exposed males was not impaired.

Bortezomib treatment does not affect the first generation Next, we examined whether pups of bortezomib exposed males were affected. In total, 6 bortezomib-derived male pups were alive and developed normally. Mean testis weight, sperm concentration and body weight in these mice were $86 \pm 0.011 \mathrm{mg}, 2.60 \times 10^{6} \pm 0.276 / \mathrm{ml}$ and $23.6 \pm 0.58 \mathrm{~g}$, respectively, and the corresponding parameters in control pups $(\mathrm{n}=13)$ were $116 \pm 0.031 \mathrm{mg}$, $2.96 \times 10^{6} \pm 0.465 / \mathrm{ml}$ and $23.0 \pm 0.36 \mathrm{~g}$, respectively. Frequency of pups surviving until the time of weaning was $48 \%$ in bortezomib-derived litters and $57 \%$ in control litters. Live-birth index and sex ratio were 13/25 (living offspring/offspring born $=52 \%)$ and $13 / 12(\hat{\delta} / q)$ in the bortezomib treated group, while $31 / 51$ (61\%) and 25/26 in controls, respectively. No statistically significant difference was detected in any of these parameters. No marked 
morphological alteration was observed when testicular histology was analyzed under light- and electron microscope after pups in both groups had reached adult age (data not shown).

\section{Bortezomib increases serum FSH levels}

Serum FSH levels were found to be significantly increased, both 45 days and 6 months after the last injection of bortezomib (Figure 3D). The levels of testicular testosterone were comparable to controls. When assessed 2 days after the cessation of bortezomib treatment, testicular testosterone levels were increased (Figure 3E).

\section{Bortezomib treatment did not impair spermatogonial proliferation}

To assess whether germ cell proliferation was impaired after bortezomib treatment, testicular sections were immunostained applying an antibody against proliferating cellular nuclear antigen (PCNA). No differences in the numbers of proliferative germ cells per seminiferous tubule were found between testes from bortezomib treated and control mice or between the pup groups (Figure 3A,
$\mathrm{B}$ arrows and $\mathrm{C}$ ), indicating that bortezomib did not interfere with spermatogonial proliferation.

Bortezomib induces germ cell apoptosis through p53 and the caspase 8- and 3 pathways

To determine how bortezomib caused testicular damage, TUNEL staining, a method to detect DNA fragmentation in nuclei was performed. Various types of germ cells, including spermatogonia, spermatocytes, and spermatids, were stained positively 2 and 45 days after the last administration of bortezomib (Figure 4D, arrows). The germ cells were TUNEL positive, while Sertoli (open triangle), peritubular (arrowhead), and interstitial cells including Leydig cells (solid triangle) did not show positive staining (Figure 4D). In control mice, only a few germ cells were TUNEL positive (Figure 4E, arrow). The number of TUNEL positive cells per seminiferous tubule was significantly increased in mice treated with bortezomib compared to controls (Figure 4F). Thus, bortezomib specifically targets the germ cells by inducing germ cell apoptosis.

Apoptosis can be induced by the intrinsic and extrinsic pathways through up-regulation of p53 and caspase 8,
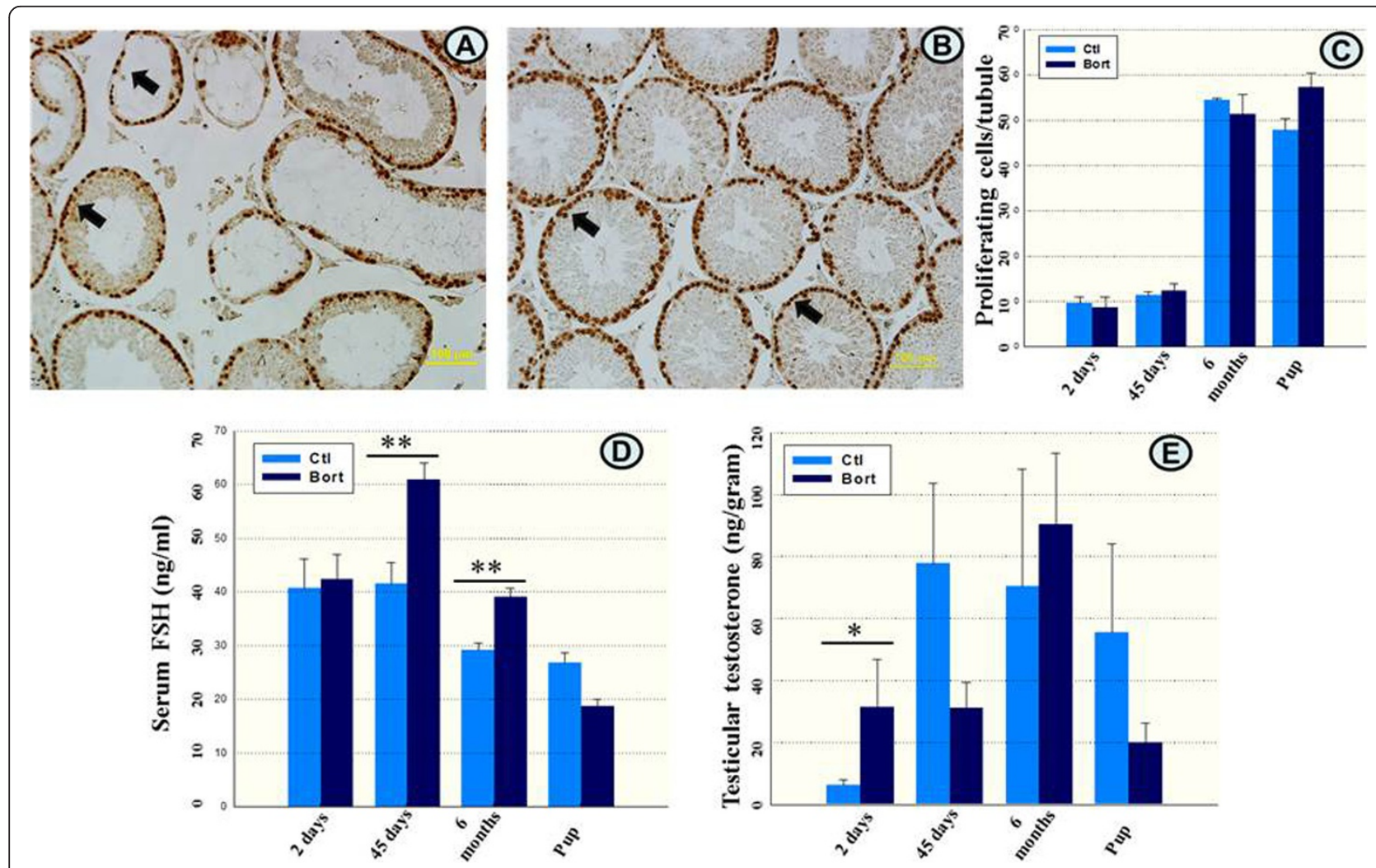

Figure 3 Immunostaining of testicular sections with PCNA and quantification of proliferating germ cells and levels of serum FSH and testicular testosterone. Proliferating germ cells in testicular sections from a mouse exposed to bortezomib 45 days earlier (A) and a corresponding control (B) labeled with brown color (arrows) after immunostaining with PCNA antibody. Quantification of proliferating germ cells per seminiferous tubule in all treated and pup groups, and their respective controls (C). Lower panels show serum FSH (D) and testicular testosterone (E) levels in 2 days, 45 days, and 6 months follow-up mice and pups of bortezomib treated animals and their corresponding controls. Magnification in (A) and (B) is 20x. Ctl: control, Bort: bortezomib. PCNA: proliferating cell nuclear antigen. 


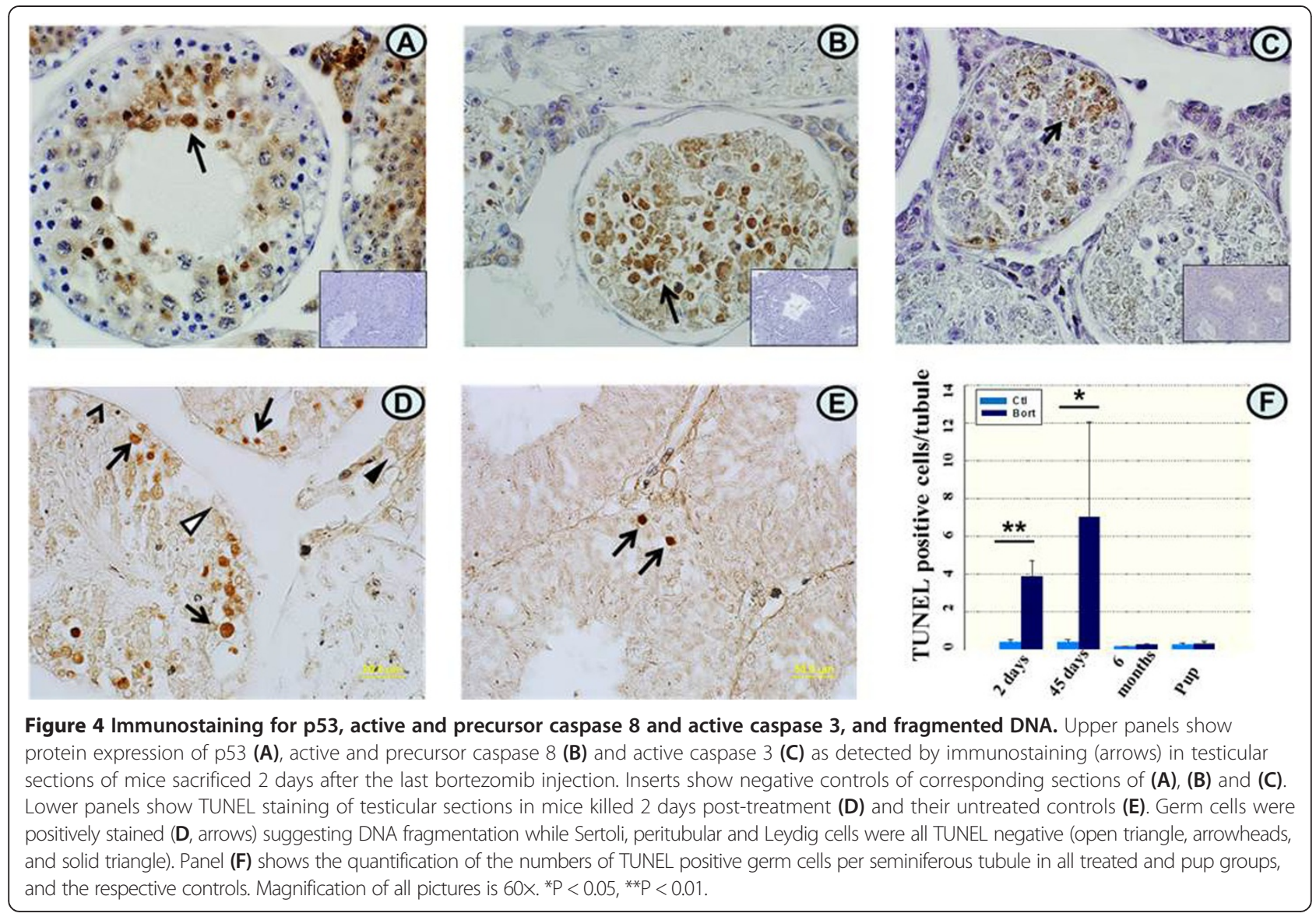

respectively, with subsequent activation of the effector caspase 3. To explore the roles of these pathways in bortezomib-induced germ cell apoptosis, testicular sections of mice killed 2 days after the last injection of bortezomib were immunostained for p53, active and precursor caspase 8 , and active caspase 3 protein expressions. In bortezomib-treated mice, numerous spermatogonia, spermatocytes and spermatids were stained positively for these markers (Figure $4 \mathrm{~A}, \mathrm{~B}$ and $\mathrm{C}$, arrows), whereas controls were negative (inserts, downright corners). This indicates that apoptosis is induced through p53 as well as through the caspase 8- and caspase 3 activating cascades.

\section{Discussion}

A significant acute decrease in the testis weight and sperm concentration was detected 2 days after the last injection of bortezomib. Thirty percent of seminiferous tubules exhibited hypospermatogenesis with arrest at the levels of spermatogonia, spermatocytes or round spermatids. Moreover, $15 \%$ of seminiferous tubule displayed $\mathrm{SCO}$. These observations indicate that bortezomib not only affects rapidly dividing germ cells but also decreases the number of quiescent spermatogonial stem cells. Thus, bortezomib is a potent gonadal toxic drug.
The damage to spermatogenetic epithelium increased when the follow-up period was extended to 45 days after bortezomib exposure. At this point, $80 \%$ seminiferous tubules exhibited hypospermatogenesis, with spermatogonia, spermatocytes and round spermatids being the most advanced germ cell type. SCO was detected nearly in $20 \%$ of examined tubules and serum FSH was elevated. The length of seminiferous tubule was significantly shorter than that in the controls. This means that bortezomib affects also the longitudinal outgrowth of seminiferous tubules in these pubertal mice and exhibits its adverse effects not only on germ cells but also on Sertoli cells. In fact, bortezomib-induced SC toxicity was further confirmed by its action killing spermatocytes and spermatids in the adlumenal compartment, which is normally protected by the blood - testis barrier created by junctions between neighboring SCs [22].

Testis weight, sperm concentration and length of the seminiferous tubule remained at a decreased level six months after bortezomib treatment, indicating that the spermatogenesis and tubular outgrowth was able to only partially recover and that bortezomib can have long-term effects on testicular function.

In the present mouse study, serum FSH levels were increased 45 days after the cessation of bortezomib 
treatment and these levels were persistently elevated up to 6 months post-treatment, suggesting long-term Sertoli cell dysfunction. Unfortunately, we could not directly study Sertoli cell function by measuring inhibin levels due to limited volumes of serum available. Significant elevated levels of testicular testosterone were also detected in mice 2 days after the last injection. We found that the level of StAR protein (steroidogenic acute regulatory protein) was higher in mice exposed to bortezomib than that in control mice (data not shown). The StAR is an important regulatory protein of steroidogenesis, and administration of bortezomib inhibits the proteasomal degradation of this protein, potentially leading to an accumulation of StAR, thereby enhancing testosterone production. Given the observation that no morphologic alterations of LCs were found and that the levels of testosterone returned to control values after 6 months, we conclude that the steroidogenic function might be unaffected after bortezomib treatment.

The seminiferous epithelium often recovers and rapidly reestablishes normal spermatogenesis through increased germ cell proliferation after toxicant withdrawal [23]. Interestingly, we did not find any such recovery taking place in the seminiferous tubules of those mice being earlier exposed to bortezomib. It is likely that bortezomib blocks the activity of the proteasome which prevents degradation of the cyclin-dependent kinase inhibitors p27Kip1 and p21Cip1, both known to arrest cell cycle progression at G1 [24], and thereby germ cell proliferation.

We can report that bortezomib caused testicular damage by triggering apoptosis in germ cells. Our results further showed that p53 induction and activation of caspases 8 and 3 play important roles in bortezomib induced germ cell apoptosis.

To evaluate whether bortezomib impairs fertility and affects offspring, we performed a mating study in males, which had been exposed to bortezomib 6months earlier. At this point, sperms are differentiated from spermatogonia that were earlier exposed to bortezomib. Fertility of these mice was preserved. There was no difference in the litter sizes and growth of pups was comparable to the controls. No statistical significant differences between pup groups were detected in testicular weights or sperm concentration after pups had reached sexual maturity. Taking together, our data demonstrate that bortezomib treatment does not impair fertility of males, and their offspring are unaffected.

Recently, Manku and colleagues demonstrated that bortezomib blocks the ability of retinoic acid to increase the expression of differentiating spermatogonial markers Stra8 and Dazl in gonocytes isolated from testes of postnatal day 3 rats [25]. Differentiation of neonatal testicular gonacytes to spermatogonia is a critical step for the establishing of the spermatogonial stem cell population, a crucial point for future fertility. In humans, this process lasts from birth up to 4-5 years of age [26], during which period, leukemia, the most common malignant disease in children, occurs. Combining Manku's finding with our data, we speculate that treatment of prepubertal boys with bortezomib could have deleterious consequences on male reproduction. Further studies to address this issue are demanded.

The bortezomib dose here used ( $1 \mathrm{mg} / \mathrm{kg}$ body weight) has previously been shown to cause $50-80 \%$ proteasome inhibition, which is clinically relevant $[9,27]$. It is also important to point out that in the present study, the impact of only a single cycle of bortezomib was evaluated. In the clinical setting, up to 9 cycles, either with a single drug or in combination with other chemotherapeutic agents is usually used. Higher cumulative doses may significantly affect spermatogenetic recovery leading to sub/infertility.

\section{Conclusion}

The systemic administration of a single cycle of bortezomib was shown to significantly affect spermatogenesis but also to cause Sertoli cell dysfunction. This damage was not fully recovered 6 months after the last administration of bortezomib and led to decreased sperm concentration and adult testicular volume. Based on our experimental data, careful monitoring of gonadal function is suggested in patients being treated with bortezomib.

\section{Materials and methods}

\section{Animals and bortezomib treatment}

Thirty-five day old (35d-old) C57B young male mice were used (B\&K Universal, Sollentuna, Sweden). At this age, the testis development corresponds to what is seen in pubertal boys. The mice were randomized into treatment and control groups, 6 animals per group. In order to mimic the clinical situation, each mouse was injected intraperitoneally (i.p) with a relevant dose of bortezomib [9] $(1.0 \mathrm{mg} / \mathrm{kg}$ of body weight, dissolved in $0.9 \% \mathrm{NaCl}$. Millennium Pharmaceuticals, Inc., MA, Cambridge, UK) while controls received $0.9 \%$ of $\mathrm{NaCl}$ (vehicle) in intervals as illustrated in Figure 5. To evaluate if bortezomib may cause acute testis damage, what would happen in the testis after it had gone through one cycle of spermatogenesis, and whether potential recovery of spermatogenesis would occur after long-time follow-up, we sacrificed mice 2, 45 days or 6 months after the last injection (Figure 5), respectively. Vehicle-treated mice were pair-fed with equal amounts of food as bortezomib-treated mice up to day 20 in order to avoid any influence of nutritional status. Blood was collected from each animal at the time of killing by heart puncture. Body, testes, epididymidis and seminal vesicles were removed and scaled. One testis from each mouse was fixed in Bouin's fixative for morphological 


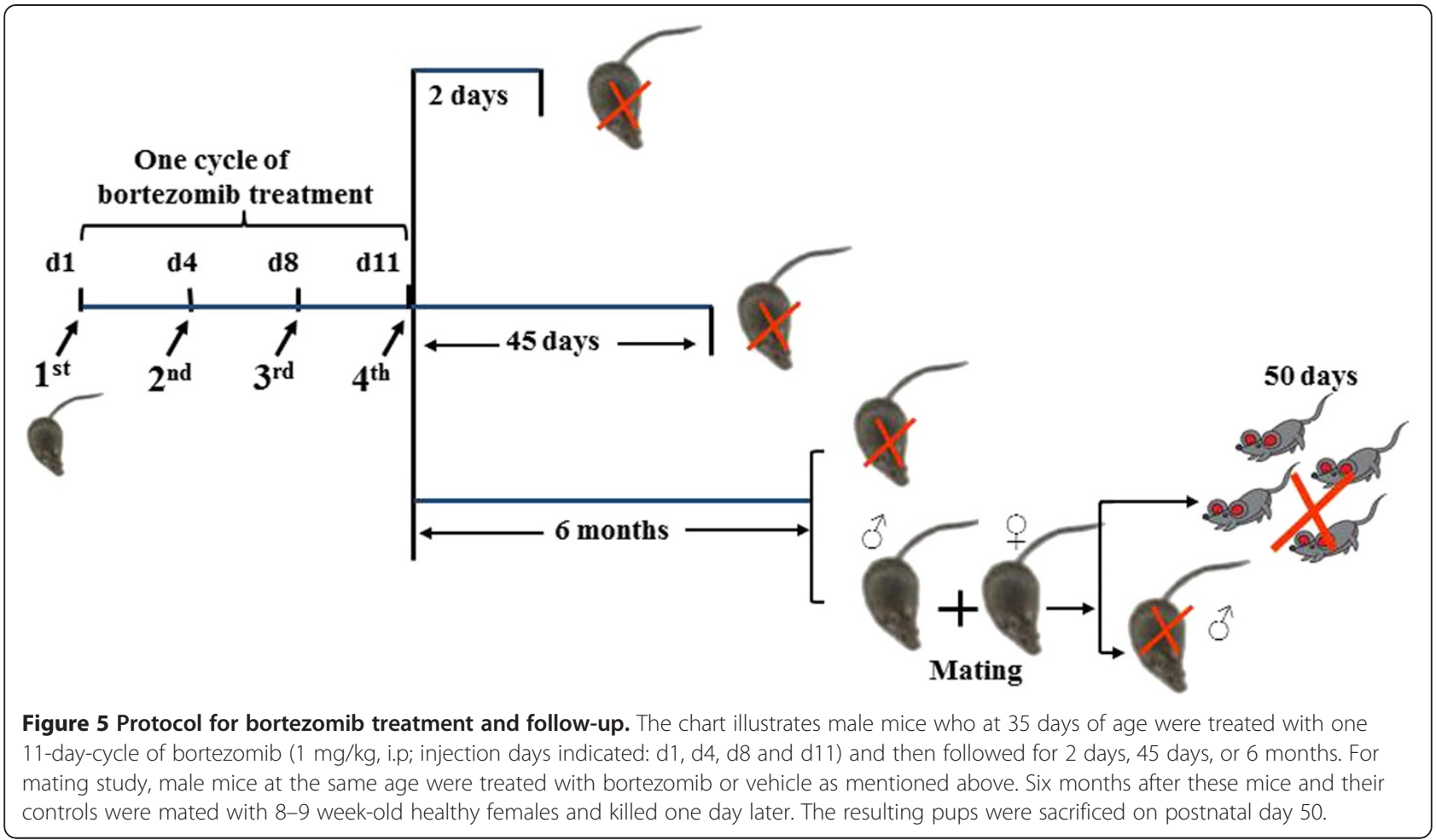

studies and calculation of length of seminiferous tubule, while part of the other testis was snap frozen and stored at $-80^{\circ} \mathrm{C}$ for testosterone measurement, and rest of the tissue was fixed in glutaraldehyde in an s-collidine buffer for electron microscopic analysis. Use and handling of animals was approved by Stockholm North Animal Ethics Committee (Permits number: N49/06, N9/07 and N283/07).

\section{Counting the number of sperms}

Dual caudate epididymis were dissected out from the epididymides of each animal and placed into 12-well Petri dishes. Each cauda was further cut into 4 pieces with iris scissors and incubated in $1 \mathrm{ml}$ of pre-warmed $\mathrm{MEM} \alpha$ medium (Invitrogen $\mathrm{AB}, \mathrm{USA}$ ) in a $37^{\circ} \mathrm{C}$ water bath for 15 minutes allowing sperms to swim out of the tissues [28]. The number of living sperms in bortezomiband vehicle-treated mice was calculated after Trypan blue staining under a light microscope.

\section{Mating study}

For mating study, in a second experiment, ten 35d-old mice in each group were treated either with bortezomib or $0.9 \%$ of $\mathrm{NaCl}$ as stated above and illustrated in Figure 5. Two out of ten mice exposed to bortezomib died and were excluded from the study. Six months after the last injection of bortezomib or vehicle, each male mouse from respective groups ( $\mathrm{n}=8$ and 10 respectively) was caged overnight together with two 8-9 week-old healthy females prior to killing (Figure 5). Fertility index of females (number of pregnant females vs. number of females mated), litter size (mean number of pups/mother), live-birth index (number of live offspring vs. number of offspring produced), sex ratio, frequency of pups surviving until the time of weaning and the nose-tail length were measured and recorded. On postnatal day 50, pups were sacrificed, testis weighed, sperm concentration calculated, and testicular histology evaluated (Figure 5).

\section{Histological examination}

The procedures for fixation and sectioning of testes followed by PAS staining of the testicular sections were conducted as described earlier [29]. Testicular histology was examined from each animal under the light microscope and compared with controls. To estimate seminiferous epithelial damage in detail, more than 100 images were captured serially from testicular sections of each mouse. Between 18-20 round shaped cross sections of tubules were selected randomly from images mentioned above, and at least 4-5 mice per group were analyzed. The relative number of seminiferous tubular cross sections containing Sertoli cell only (SCO) or spermatogonia, spermatocytes, round spermatids and elongating/sperm as the most advanced germ cell type were recorded and presented as mean values \pm S.E.M as whole group. For electron microscopy, testicular tissues were fixed and analyzed in the same manner as described previously [30]. 


\section{Calculation of the length of seminiferous tubules}

In order to measure the length of seminiferous tubules, the diameters of 18-20 round cross-cords randomly selected from each mouse were measured. The proportion of interstitial area was determined by point-counting methodology [31] and seminiferous tubules area was converted by whole testis area (referred to as $100 \%$ ) subtracting the proportion of interstitial area. Testicular length in each animal was calculated using the formula [32]:

Length of the tubule $(\mathrm{m})=$

$\frac{\text { Volume of the testis }(\mathrm{ml}) \times \text { cord/tubule's area }(\%)}{\pi \times(\text { diameter of the cord } / \text { tubule }(\mu \mathrm{m}) / 2)^{2}}$

and expressed as mean values \pm S.E.M as whole group (Table 1).

\section{Immunohistochemistry}

Antigen retrieval was performed in citrate buffer ( $\mathrm{pH}$ 6.0) containing $0.01 \%$ Tween- 20 at $95^{\circ} \mathrm{C}$ for $20 \mathrm{~min}$ in a microwave. Testicular sections were incubated with $10 \%$ of normal goat serum (for all antibodies) and $3 \%$ $\mathrm{H}_{2} \mathrm{O}_{2}$ at room temperature (RT) for 15 minutes, respectively. Thereafter, rabbit anti-mouse p53, active and precursor caspase 8 (Santa-Cruz, sc-28206, sc-7890 respectively, California, USA) and active caspase 3 (Ab-cam, ab-2302, Cambridge, UK) antibodies were all at a 1:50 dilution applied overnight at $4^{\circ} \mathrm{C}$. Next day, sections were incubated with a secondary goat anti-rabbit biotinylated antibody at a 1:300 dilution for $1 \mathrm{~h}$ at RT followed by incubation with $\mathrm{ABC}$ agents and $\mathrm{DAB}$ substrate (all purchased from Vector Laboratories, BA-1000, Burlingame, USA), as described earlier [29].

\section{In situ apoptosis and cell proliferation}

TUNEL positive cells in testicular sections were detected by terminal deoxyribonucleotidyl transferase-mediated dUTP nick end labeling as described earlier [30]. Cell proliferation was detected by staining of testicular sections with a rabbit anti-mouse proliferating cell nuclear antigen (PCNA) antibody (1:50, Santa Cruz, sc-7907) followed by incubation with a secondary antibody, $\mathrm{ABC}$ agents and DAB substrate as described above. For calculation of TUNEL positive and proliferating germ cells, at least 50 round shaped seminiferous tubule cross-sections from testicular sections of each mouse $(n=4)$ were counted. The numbers of TUNEL positive and proliferating cells were expressed as positive cells per seminiferous tubule.

\section{Measurement of serum FSH and testicular testosterone} FSH levels were measured in serum with a rat FSH ELISA kit (Biocode-Hycel, France, Cat: AE R004) according to the manufacturer's instructions. The concentration of serum $\mathrm{FSH}$ was expressed in $\mathrm{ng} / \mathrm{ml}$. Intratesticular testosterone concentrations were assayed as described earlier [33]. Briefly, testicular tissues (30-50 mg) obtained from individual mice were homogenized by sonication $(2 \times 20$ sec. $)$ in a sodium phosphate buffer and then centrifuged at $10.000 \times \mathrm{g}$ for $10 \mathrm{~min}$. Testosterone concentrations in the supernatants were determined employing the coat-a-count RIA kit (Diagnostic products Corp., Los Angeles, GA, USA) according to the manufacturer's instructions and expressed as ng/gram tissue.

\section{Statistical analysis}

Results in Table 1 are presented as mean values \pm SEM. Differences between two groups were tested by $t$-test followed by a Mann-Whitney Rank Sum Test if the normality test failed. Differences were considered statistically significant for $\mathrm{p}$-values $<0.05$.

\section{Abbreviations}

PAS staining: Periodic acid-Schiff staining; MEMa medium: Minimal essential medium; SC: Sertoli cell; SCO: Sertoli cell only tube; LC: Leydig cell; FSH: Follicle-stimulating hormone; TUNEL: Terminal deoxynucleotidyl transferase dUTP nick end labeling; DAB: 3, 3'-diaminobenzidine; UPS: Ubiquitin and proteasome dependent proteolytic system.

\section{Competing interests}

The authors declare that they have no competing interests.

\section{Authors' contributions}

$\mathrm{MH}$ : Writing manuscript. MH, EE, AM, LS: Conception and design. MH, KJ, AM: Analysis and interpretation of data (statistical and histological analysis). EE, OS, KJ, KS, AM, LS: Review and/revision of the manuscript. AM, KS: Technical and/material support. OS, AM, LS: Study supervision. All authors read and approved the final manuscript.

\section{Acknowledgements}

The authors thank Dr Farasat Zaman for scientific discussion.

\section{Grant support}

This study was supported financially by the Swedish Research Council (Finnish Academy); Stiftelsen Barnavård; Stiftelsen Frimurare Barnhuset i Stockholm; the Swedish Child Cancer Foundation; Stiftelsen Samariten; Dagmar Ferb's Fund for Cancer; Stiftelsen Goljes Minne; Stiftelsen Anna-Brita och Bo Castegrens Minne; Karolinska Institutets forskningsstiftelse and HKH Kronprinsessan Lovisas förening för barnasjukvård. Mi Hou was supported by grants from the AFA Sjukförsäkringsaktiebolags Jubileumsstiftelse and Stiftelsen Svenska Sällskapet för Medicinsk Forskning.

\section{Author details}

'Department of Women's and Children's Health, Astrid Lindgren Children's Hospital, Pediatric Endocrinology Unit Q2:08, Karolinska Institutet \& University Hospital, SE-171 76 Stockholm, Sweden. ${ }^{2}$ Pediatric Hematology and Oncology, Hospital for Children and Adolescen, University of Helsinki, FIN-00290 Helsinki, Finland. ${ }^{3}$ Department of Anatomy and Cell Biology, Justus-Liebig-University of Giessen, Aulweg 123, 35385 Giessen, Germany.

Received: 4 March 2014 Accepted: 5 June 2014

Published: 20 June 2014

\section{References}

1. Groll M, Potts BC: Proteasome structure, function, and lessons learned from beta-lactone inhibitors. Curr Top Med Chem 2011, 11:2850-2878.

2. Frezza M, Schmitt S, Dou QP: Targeting the ubiquitin-proteasome pathway: an emerging concept in cancer therapy. Curr Top Med Chem 2011, 11:2888-2905 
3. Ludwig H, Khayat D, Giaccone G, Facon T: Proteasome inhibition and its clinical prospects in the treatment of hematologic and solid malignancies. Cancer 2005, 104:1794-1807.

4. Adams J, Behnke M, Chen S, Cruickshank AA, Dick LR, Grenier L, Klunder JM, $M a Y T$, Plamondon L, Stein RL: Potent and selective inhibitors of the proteasome: dipeptidyl boronic acids. Bioorg Med Chem Lett 1998, 8:333-338.

5. Chauhan D, Bianchi G, Anderson KC: Targeting the UPS as therapy in multiple myeloma. BMC Biochem 2008, 9(Suppl 1):S1.

6. Di Bella N, Taetle R, Kolibaba K, Boyd T, Raju R, Barrera D, Cochran EW Jr, Dien PY, Lyons R, Schlegel PJ, Vukelja SJ, Boston J, Boehm KA, Wang Y, Asmar L: Results of a phase 2 study of bortezomib in patients with relapsed or refractory indolent lymphoma. Blood 2010, 115:475-480.

7. Messinger $Y$, Gaynon P, Raetz E, Hutchinson R, Dubois S, Glade-Bender J, Sposto R, van der Giessen J, Eckroth E, Bostrom BC: Phase I study of bortezomib combined with chemotherapy in children with relapsed childhood acute lymphoblastic leukemia (ALL): a report from the therapeutic advances in childhood leukemia (TACL) consortium. Pediatr Blood Cancer 2010, 55:254-259.

8. Richardson PG, Barlogie B, Berenson J, Singhal S, Jagannath S, Irwin D, Rajkumar SV, Srkalovic G, Alsina M, Alexanian R, Siegel D, Orlowski RZ, Kuter D, Limentani SA, Lee S, Hideshima T, Esseltine DL, Kauffman M, Adams J, Schenkein DP, Anderson KC: A phase 2 study of bortezomib in relapsed, refractory myeloma. N Engl J Med 2003, 348:2609-2617.

9. Eriksson E, Zaman F, Chrysis D, Wehtje H, Heino TJ, Savendahl L: Bortezomib is cytotoxic to the human growth plate and permanently impairs bone growth in young mice. PLoS One 2012, 7:e50523.

10. Sutovsky P: Ubiquitin-dependent proteolysis in mammalian spermatogenesis, fertilization, and sperm quality control: killing three birds with one stone. Microsc Res Tech 2003, 61:88-102.

11. Baarends WM, van der Laan R, Grootegoed JA: Specific aspects of the ubiquitin system in spermatogenesis. J Endocrinol Invest 2000, 23:597-604.

12. Rajapurohitam V, Bedard N, Wing SS: Control of ubiquitination of proteins in rat tissues by ubiquitin conjugating enzymes and isopeptidases. Am J Physiol Endocrinol Metab 2002, 282:E739-E745.

13. Baarends WM, Roest HP, Grootegoed JA: The ubiquitin system in gametogenesis. Mol Cell Endocrinol 1999, 151:5-16.

14. Dickins RA, Frew IJ, House CM, O'Bryan MK, Holloway AJ, Haviv I, Traficante N, de Kretser DM, Bowtell DD: The ubiquitin ligase component Siah1a is required for completion of meiosis I in male mice. Mol Cell Biol 2002, 22:2294-2303.

15. Sutovsky P, Neuber E, Schatten G: Ubiquitin-dependent sperm quality control mechanism recognizes spermatozoa with DNA defects as revealed by dual ubiquitin-TUNEL assay. Mol Reprod Dev 2002, 61:406-413.

16. Ryu KY, Sinnar SA, Reinholdt LG, Vaccari S, Hall S, Garcia MA, Zaitseva TS, Bouley DM, Boekelheide K, Handel MA, Conti M, Kopito RR: The mouse polyubiquitin gene Ubb is essential for meiotic progression. Mol Cell Biol 2008, 28:1136-1146.

17. Sinnar SA, Small CL, Evanoff RM, Reinholdt LG, Griswold MD, Kopito RR, Ryu KY: Altered testicular gene expression patterns in mice lacking the polyubiquitin gene Ubb. Mol Reprod Dev 2011, 78:415-425.

18. Kwon J, Mochida K, Wang YL, Sekiguchi S, Sankai T, Aoki S, Ogura A, Yoshikawa Y, Wada K: Ubiquitin C-terminal hydrolase L-1 is essential for the early apoptotic wave of germinal cells and for sperm quality control during spermatogenesis. Biol Reprod 2005, 73:29-35.

19. Luo J, Megee S, Dobrinski I: Asymmetric distribution of UCH-L1 in spermatogonia is associated with maintenance and differentiation of spermatogonial stem cells. J Cell Physio/ 2009, 220:460-468.

20. Wang YL, Liu W, Sun YJ, Kwon J, Setsuie R, Osaka H, Noda M, Aoki S, Yoshikawa Y, Wada K: Overexpression of ubiquitin carboxyl-terminal hydrolase L1 arrests spermatogenesis in transgenic mice. Mol Reprod Dev 2006, 73:40-49.

21. Bedard N, Hingamp P, Pang Z, Karaplis A, Morales C, Trasler J, Cyr D, Gagnon C, Wing SS: Mice lacking the UBC4-testis gene have a delay in postnatal testis development but normal spermatogenesis and fertility. Mol Cell Biol 2005, 25:6346-6354.

22. Meistrich ML: Stage-specific sensitivity of spermatogonia to different chemotherapeutic drugs. Biomed Pharmacother 1984, 38:137-142.

23. Boekelheide K: Mechanisms of toxic damage to spermatogenesis. J Natl Cancer Inst Monogr 2005, 34:6-8.

24. Russo A, Fratto ME, Bazan V, Schiro V, Agnese V, Cicero G, Vincenzi B, Tonini $G$, Santini D: Targeting apoptosis in solid tumors: the role of bortezomib from preclinical to clinical evidence. Expert Opin Ther Targets 2007, 11:1571-1586

25. Manku G, Wing SS, Culty M: Expression of the ubiquitin proteasome system in neonatal rat gonocytes and spermatogonia: role in gonocyte differentiation. Biol Reprod 2012, 87:44.

26. Paniagua R, Nistal M: Morphological and histometric study of human spermatogonia from birth to the onset of puberty. J Anat 1984, 139(Pt 3):535-552.

27. Bold R: Development of the proteasome inhibitor Velcade (Bortezomib)" by Julian Adams, Ph.D., and Michael Kauffman, M.D., Ph.D. Cancer Invest 2004, 22:328-329.

28. Pakarainen T, Zhang FP, Makela S, Poutanen M, Huhtaniemi I: Testosterone replacement therapy induces spermatogenesis and partially restores fertility in luteinizing hormone receptor knockout mice. Endocrinology 2005, 146:596-606.

29. Hou M, Andersson M, Eksborg S, Soder O, Jahnukainen K: Xenotransplantation of testicular tissue into nude mice can be used for detecting leukemic cell contamination. Hum Reprod 2007, 22:1899-1906.

30. Hou M, Chrysis D, Nurmio M, Parvinen M, Eksborg S, Soder O, Jahnukainen K: Doxorubicin induces apoptosis in germ line stem cells in the immature rat testis and amifostine cannot protect against this cytotoxicity. Cancer Res 2005, 65:9999-10005

31. Lue YH, Hikim AP, Swerdloff RS, Im P, Taing KS, Bui T, Leung A, Wang C: Single exposure to heat induces stage-specific germ cell apoptosis in rats: role of intratesticular testosterone on stage specificity. Endocrinology 1999, 140:1709-1717.

32. Leidl W, Bentley Ml, Gass GH: Longitudinal growth of the seminiferous tubules in LH and FSH treated rats. Andrologia 1976, 8:131-136.

33. Robertson KM, Schuster GU, Steffensen KR, Hovatta O, Meaney S, Hultenby K, Johansson LC, Svechnikov K, Soder O, Gustafsson JA: The liver X receptor-\{beta\} is essential for maintaining cholesterol homeostasis in the testis. Endocrinology 2005, 146:2519-2530.

\section{doi:10.1186/1476-4598-13-155}

Cite this article as: Hou et al:: Bortezomib treatment causes long-term testicular dysfunction in young male mice. Molecular Cancer 2014 13:155.

\section{Submit your next manuscript to BioMed Central and take full advantage of:}

- Convenient online submission

- Thorough peer review

- No space constraints or color figure charges

- Immediate publication on acceptance

- Inclusion in PubMed, CAS, Scopus and Google Scholar

- Research which is freely available for redistribution 